\title{
Solid pseudopapillary carcinoma of pancreas
}

INSERM

\section{Source}

INSERM. (1999). Orphanet: an online rare disease and orphan drug data base. Solid pseudopapillary carcinoma of pancreas. ORPHA:424065

Solid pseudopapillary carcinoma of the pancreas is a rare carcinoma of the pancreas characterized by a variable combination of nonspecific signs and symptoms, such as abdominal pain, jaundice, abdominal fullness, anorexia, nausea, vomiting, and weight loss. One-third of the patients are asymptomatic. The tumor has low malignant potential, but can invade locally. 